\title{
Constitución del Instituto Mixto de Investigación Biosanitaria Militar IMIDEF: la realidad de un deseo
}

El pasado 9 de abril tuvo lugar la firma por el Ministro de Defensa, Excmo Sr D. Pedro Morenés, del Convenio de Constitución del Instituto Mixto de Investigación Biosanitaria Militar (IMIDEF), ratificando la firma llevada a cabo previamente por el Rector Magnífico de la Universidad de Alcalá, Excmo Sr D. Fernando Galván. Con este hecho se alcanzó una vieja aspiración cuyos primeros intentos se remontan a 2005 y que ha sido posible gracias a la perseverancia y el trabajo de muchas personas desde entonces.

Los Institutos de Investigación han sido promovidos por todos los grandes centros públicos españoles como paso previo a la realización de investigación de alto nivel. Deben de considerarse como útiles necesarios para canalizar debidamente los esfuerzos del personal investigador hacia fines concretos, dentro de líneas estratégicas marcadas previamente. Constituyen la base de la organización investigadora competitiva en cualquier ámbito y facilitan la captación de fondos económicos necesarios para su desarrollo, más en la actualidad, cuando la escasez de medios es manifiesta y sólo será adjudicada a los grupos que muestren estructuras que garanticen la consecución de los proyectos emprendidos, su difusión y la aplicación clínica secundaria a la investigación «traslacional». Son entidades que tienden a ordenar y orientar las expectativas investigadoras de los profesionales de la salud que, dispersas con alta frecuencia, dilapidan esfuerzos personales y económicos disminuyendo su rentabilidad.

El IMIDEF responde a las competencias del Ministerio de Defensa en la «preparación, el desarrollo y la ejecución de la política de defensa y la gestión de la administración militar y por ello de los centros, servicios y establecimientos dependientes del mismo, incluidos todos los que integran la Sanidad Militar, al objeto de realizar la actividad asistencial, docente e investigadora como parte fundamental del apoyo a la Fuerza».

Como todos los institutos de investigación biosanitaria, pivota sobre tres puntos básicos: un hospital de reconocido prestigio, una universidad que garantice capacidad investigadora, y un órgano gestor. Está constituido a través de la «asociación de personal docente e investigador de la Universidad de Alcalá (UAH) y de grupos de investigación en el ámbito de la Inspección General de Sanidad de la Defensa (IGESAN) integrados en el Hospital Central de la Defensa «Gómez Ulla» como núcleo básico del IMIDEF, en los Institutos de Medicina Preventiva y de Toxicología, y en todos aquéllos que, dependiendo de la Subsecretaría de Defensa, se consideren de interés biosanitario, con base en el artículo 88 de la Ley 14/2007 de 3 de julio, de Investigación Biomédica y de conformidad con lo regulado en el RD 339/2004, de 27 de febrero».
La puesta en marcha del IMIDEF hace necesaria la activación de la investigación en nuestro medio a través de la Unidad de Investigación recientemente creada en el Hospital Central de la Defensa Gómez Ulla, abierta a todos los miembros de las estructuras y unidades citadas en el apartado previo, dentro de cuyas misiones figura la organización de cursos y actividades para su promoción, con organismos de apoyo a la investigación desde el punto de vista metodológico, estadístico, seguimiento, presentación de trabajos, medios de captación de fondos, ayuda en la gestión de los mismos y orientación en las tareas administrativas, con una especial focalización en las múltiples áreas temáticas asumidas como estratégicas en el documento del convenio, dieciséis en la actualidad.

La organización del IMIDEF cuenta con:

a) Órganos de gobierno: Consejo Rector y la Comisión Mixta de Dirección y Seguimiento.

b) Órganos de consulta, conformados por dos Comités Científicos, Externo e Interno.

c) Órgano de dirección ejecutiva que corresponde al Director del IMIDEF, a la vez Director Científico del mismo.

d) Órgano de gestión, que ofrece el soporte necesario en las áreas económico-administrativas y de recursos humanos y que actuará como oficina de transferencia de resultados de investigación.

El IMIDEF abre un futuro esperanzador, inicialmente duro y progresivamente complejo, que exige la voluntad y el esfuerzo de todos los miembros de Sanidad Militar, especialmente el de nuestros compañeros más jóvenes, hasta llegar a conseguir la densidad científica necesaria para su acreditación por el Instituto de Salud Carlos III. Este proceso tardará algunos años, pero no se conseguirá si no se comienza a trabajar desde este momento.

Todo ello redundará en beneficio común, para Sanidad Militar como institución y, por añadidura, para sus miembros implicados en su consecución. Hoy es una plataforma de despegue absolutamente necesaria. Después estaremos en la élite de la investigación, imprescindible para facilitar un apoyo de alta calidad a la Fuerza y un servicio a la sociedad civil en áreas hasta ahora poco exploradas.

Luis Callol Sánchez General de Brigada Médico (R) 


\section{OTRAS DISPOSICIONES MINISTERIO DE DEFENSA} Pagés Miravé» en su sexta convocatoria.

Mediante la Orden DEF/2204/2012, de 3 de octubre, se procedió a promover la convocatoria del premio «Fidel Pagés Miravé», creado por Orden DEF/1760/2007, de 11 de junio, con el fin de incentivar y premiar los trabajos, tanto de investigación en Ciencias de la Salud como en Ciencia Histórica de Sanidad Militar.

En dicha Orden se determina que un jurado, presidido por el Inspector General de Sanidad de la Defensa, propondrá la concesión del premio, que se otorgará por Orden del Ministro de Defensa.

El jurado se reunió a tal efecto el 24 de junio de 2013 y ha propuesto la concesión del premio.

En su virtud, de acuerdo con las facultades que me confiere el artículo 4.1.b) de la Ley 50/1997, de 27 de noviembre, del Gobierno, dispongo:

Apartado único. Otorgamiento.

Se otorga el Premio «Fidel Pagés Miravé», en su sexta convocatoria, al siguiente trabajo:

a) Premio «Comandante médico Fidel Pagés Miravé» al trabajo titulado «Análisis de las repatriaciones por causas médicas en el contingente español de la ISAF durante los años 2009-2012 y de los fallecimientos ocurridos en Afganistán desde el inicio de la misión hasta diciembre de 2012» del que son autores: el Teniente Coronel del Cuerpo Militar de Sanidad (Medicina), don Juan Torres León; la Comandante Médico, doña María Jesús Sánchez Carrillo; el Capitán Médico, don Francisco Javier Membrillo de Novales, y la Teniente Médico, doña María Navarro Téllez, todos ellos pertenecientes al servicio de Medicina Interna del Hospital Central de la Defensa Gómez Ulla.

\section{Disposición final única. Entrada en vigor.}

La presente Orden entrará en vigor el día siguiente al de su publicación en el «Boletín Oficial del Estado».

Madrid, 10 de julio de 2013.-El Ministro de Defensa, Pedro Morenés Eulate. 


\section{OTRAS DISPOSICIONES MINISTERIO DE DEFENSA}

Orden DEF/1447/2013, de 17 de julio, por la que se publica la séptima convocatoria del premio «Fidel Pagés Miravé».

De acuerdo con la Orden DEF/1760/2007, de 11 de junio, por la que se crea el premio «Fidel Pagés Miravé», la Inspección General de Sanidad promueve su séptima convocatoria, fijando, a través de esta Orden Ministerial, las bases y requisitos.

\section{Primera. Denominación.}

Dada la posibilidad de autores no españoles que se contempla en la base segunda, se considera Premio Internacional Fidel Pagés Miravé desde el año 2011.

\section{Segunda. Concurrentes.}

Podrán optar al premio personas físicas, españolas o extranjeras, a título individual o integradas en grupos de trabajo.

Tercera. Trabajos.

Los trabajos, objeto del presente premio, serán inéditos, no considerándose como tales los que constituyan la totalidad o la mayor parte de Tesis Doctorales defendidas en cualquier Universidad, pública o privada y que hayan sido publicadas en cualquier soporte incluido el electrónico. Deberán estar escritos en español o inglés, las páginas irán numeradas y escritas en una sola cara a doble espacio en formato DIN A-4 y fuente Arial tamaño 12, con una extensión no mayor de 50 páginas. Serán presentados en papel (por quintuplicado) y en soporte informático. Se incluirá un resumen no superior a una página en español e inglés. El tema será un trabajo original en Ciencias de la Salud, con especial exigencia a la metodología científica de investigación, se valorará su relación o utilidad para la Sanidad Militar; o un trabajo original en Ciencia Histórica de la Sanidad Militar con igual exigencia metodológica y que se base en su mayor parte en fuentes primarias.

\section{Cuarta. Identificación.}

Los trabajos se presentarán con título y firmados bajo lema o seudónimo, no incluyéndose datos que identifiquen de forma directa a sus autores y dentro del mismo envío se incluirá un sobre cerrado, en cuyo exterior figure el Título del trabajo, el Lema o seudónimo y que contenga un documento con los siguientes datos: Título, Lema o seudónimo, Autor o autores (los militares empleo y destino), dirección completa, teléfono, fax o e-mail y autorización para su publicación en la Revista «Sanidad Militar» firmada por el autor o autores del trabajo. Los trabajos se remitirán a la Inspección General de Sanidad de la Defensa, Hospital Central de la Defensa "Gómez Ulla», Glorieta del Ejército, 1, 28047 Madrid, España.

\section{Quinta. Plazo de presentación.}

Los trabajos podrán presentarse desde el día siguiente a la publicación de esta convocatoria hasta el 15 de mayo de 2014. Los trabajos recibidos después de la citada fecha o que no cumplan con las especificaciones establecidas, serán rechazados. 
Sexta. Premio.

Se establecen los siguientes premios: Premio «Comandante médico Fidel Pagés Miravé», dotado con $6.000 €$ y un accésit de $3.000 €$. En caso de ser premiado un trabajo realizado por varios autores, el premio se entregará al primer firmante.

Séptima. Jurado.

El Jurado estará compuesto de acuerdo con lo estipulado en la disposición sexta de la Orden DEF/1760/2007, de 11 de junio («BOE» número 144, de fecha 16 de junio de 2007). La decisión del jurado será inapelable, se comunicará a los premiados y se hará pública en el "Boletín Oficial de la Defensa» («BOD»), a través de la Revista «Sanidad Militar», y en todos los Centros dependientes de la Inspección General de Sanidad Militar. El Jurado podrá considerar desierto el premio.

Octava. Resolución y publicidad.

El Premio se otorgará por orden del Ministro de Defensa, que se publicará en el «Boletín Oficial del Estado», a propuesta del Jurado.

Novena. Publicación de los trabajos.

Todos los trabajos se considerarán presentados para su publicación en la revista Sanidad Militar. Los trabajos premiados serán considerados aceptados para su publicación, en su totalidad, o en un resumen que se solicitaría a los autores, en un número ordinario o extraordinario de la Revista de Sanidad Militar o en otro soporte a determinar por la Inspección General de Sanidad y la Subdirección General de Publicaciones y Patrimonio del Ministerio de Defensa.

Décima. Entrega de premios.

La entrega de los premios se realizará en acto público en fecha próxima al 23 de septiembre, día del fallecimiento del Comandante Fidel Pagés Miravé.

Undécima.

La participación supone la aceptación de todas y cada una de estas bases y la renuncia a cualquier reclamación.

Madrid, 17 de julio de 2013.-El Ministro de Defensa, Pedro Morenés Eulate. 